Vio Nita, Tutik Astuti "Perbedaan Pengetahuan Pre dan Post Penyuluhan Kesehatan Tentang Kanker Serviks pada Wanita di Dusun RinginSari Bokoharjo Prambanan Sleman Daerah Istimewa Yogyakarta" (hal 169-175)

Received

Revisied

Acceptep

06 Juni 2019

28 Juli 2019

15 Oktober 2019

\title{
PERBEDAAN PENGETAHUAN PRE DAN POST PENYULUHAN KESEHATAN TENTANG KANKER SERVIKS PADA WANITA DI DUSUN RINGINSARI BOKOHARJO PRAMBANAN SLEMAN DAERAH ISTIMEWA YOGYAKARTA
}

\author{
Vio Nita ${ }^{1}$, Tutik Astuti ${ }^{2}$ \\ Universitas Respati Yogyakarta \\ Email : vyoo7392@gmail.com \\ Universitas Respati Yogyakarta \\ Email : ninnanku@gmail.com
}

\begin{abstract}
ABSTRAK
Pendahuluan : Kanker serviks merupakan kanker kedua di dunia yang paling banyak diderita wanita setelah kanker payudara terutama di Negara Berkembang seperti Indonesia. Faktor yang membuat telambatnya deteksi dini yang dilakukan oleh wanita karena kurangnya pengetahuan tentang kanker serviks, misalnya untuk menjaga kebersihan daerah kewanitaan (vagina) sangatlah penting dilakukan khususnya untuk wanita dan bagaimana cara mendeteksi dini agar wanita tidak terkena kanker serviks. Tujuan : Untuk mengetahui perbedaan pengetahuan Pre dan Post Penyuluhan Kesehatan Tentang Kanker Serviks Pada Wanita Di Dusun Ringinsari Bokoharjo Prambanan Sleman Daerah Istimewa Yogyakarta. Metode : Metode yang digunakan yaitu quasi eksperiment dengan pendekatan "One Groups. Pretest-Posttest Design". Jumlah sampel yaitu 35 orang. Pengambilan sampel pada penelitian ini yaitu menggunakan teknik sampling Accidental Sampling. Hasil : Sebagian besar $(45,71 \%)$ pre test pengetahuan kanker serviks dan deteksi dini dalam kategori kurang dan setelah diberi penyuluhan sebagian besar $(71,43 \%)$ dalam kategori baik. Diketahui $p_{-}$value $0,000<0,05$. Kesimpulan : Ada perbedaan antara pengetahuan tentang kanker serviks sebelum diberi penyuluhan dan setelah diberi penyuluhan.
\end{abstract}

\section{Kata Kunci : Penyuluhan, Kanker Serviks}

\begin{abstract}
Background: Cervical cancer is the second cancer in the world that affects most women after breast cancer, especially in developing countries such as Indonesia. Factors that make the early detection done by women due to lack of knowledge about cervical cancer, for example to maintain the cleanliness of the female area (vagina) is very important, especially for women and how to detect early so that women are not affected by cervical cancer. Objective : To determine the differences in Pre and Post knowledge of Health Counseling about Cervical Cancer in Women in Ringinsari Bokoharjo Prambanan Sleman Special Region of Yogyakarta.Method: The method used is a quasi experiment with the "One Groups Pretest-Posttest Design" approach. The number of samples is 35 people. Sampling in this study is using accidental sampling sampling technique.Results: Most (45.71\%) pre test knowledge of cervical cancer and early detection in the less category and after being given counseling most (71.43\%) were in the good category. Known p_value 0,000 <0,05. Conclusion: There is a difference between knowledge about cervical cancer before being given counseling and after being given counseling.
\end{abstract}


Jurnal Kesehatan Karya Husada, No 7 Vol 2 Tahun 2019

PISSN 2337649X/EISSN 2655-8874

Vio Nita, Tutik Astuti "'Perbedaan Pengetahuan Pre dan Post Penyuluhan Kesehatan Tentang Kanker Serviks pada Wanita di Dusun RinginSari Bokoharjo Prambanan Sleman Daerah Istimewa Yogyakarta" (hal 169-175)

Keywords: Extension, Cervical Cancer 
Jurnal Kesehatan Karya Husada, No 7 Vol 2 Tahun 2019

PISSN 2337649X/EISSN 2655-8874

Vio Nita, Tutik Astuti "Perbedaan Pengetahuan Pre dan Post Penyuluhan Kesehatan Tentang Kanker Serviks pada Wanita di Dusun RinginSari Bokoharjo Prambanan Sleman Daerah lstimewa Yogyakarta" (hal 169-175)

\section{PENDAHULUAN}

Angka prevalensi kejadian kanker di dunia masih menduduki peringkat tertinggi setelah penyakit kardiovaskular dan menjadi penyebab utama kematian. Badan Organisasi Kesehatan Dunia / World Health Organization (WHO) mengungkapkan, angka kesakitan akibat kanker di dunia pada tahun 2012 sekitar 14,1 juta dengan angka kematian 8,2 juta. Sebelumnya, tahun 2008 angka kesakitan akibat kanker 12,7 juta dengan angka kematian sebesar 7,6 juta. Indonesia sendiri angka kejadian kanker masih dibilang cukup tinggi, berdasarkan Riset Kesehatan Dasar (Riskesdas) yang dilakukan pada tahun 2010 menyebutkan bahwa angka kejadian tumor maupun kanker di Indonesia sendiri mencapai 1,4 per 1000 penduduk (sekitar 330.000 orang) (Riskesdas, 2013). Sedangkan, pada tahun 2013 jumlah penderita kanker meningkat menjadi 347.792 orang.

Kanker serviks merupakan kanker kedua di dunia yang paling banyak diderita wanita setelah kanker payudara terutama di Negara Berkembang seperti Indonesia. IARC
(International Agency For Research On Cancer) pada tahun 2012 menyebutkan prevalensi kejadian kanker payudara sebesar 40 per 100.000 wanita dan kanker leher rahim / serviks sebesar 26 per 100.000 wanita. Angka prevalensi kejadian untuk kanker servik tahun 2012 ada 528.000 kasus dengan angka kematian 266.000 kasus. Sistem Informasi Rumah Sakit (SIRS) di Indonesia pada tahun 2010, kasus rawat inap pada kanker payudara sebesar 12.014 kasus $(28,7 \%)$ sedangkan untuk kanker leher Rahim/serviks sebesar 5.349 kasus $(12,8 \%)$ di seluruh rumah sakit. Pengetahuan dan kesadaran masyarakat terutama wanita terhadap kesehatan reproduksinya dinilai masih kurang. Selama ini penyuluhan kesehatan juga dinilai masih kurang untuk masyarakat yang tinggal di pedesaan. Penyuluhan merupakan metode yang baik untuk memberikan informasi kesehatan reproduksinya kepada masyarakat khususnya wanita, tentang kanker serviks dan cara mendeteksi dini kanker serviks sehingga dapat menurunkan angka kematian. 


\section{METODE PENELITIAN}

\section{HASIL DAN PEMBAHASAN}

Desain penelitian ini adalah quasieksperiment yaitu suatu penelitian dengan melakukan kegiatan percobaan (eksperiment) yang bertujuan untuk mengetahui gejala dan pengaruh yang timbul sebagai akibat dari adanya perlakuan tertentu (Arifin, 2014). Jenis rancangan "One Groups PretestPosttest Design" yaitu variabel diukur/diobservasi terlebih dahulu sebelum diberikan perlakuan (pre-test) setelah itu dilakukan perlakuan dan setelah perlakuan dilakukan pengukuran/obeservasi (post-test) (Sugiyono, 2012). Populasi penelitian ini adalah wanita usia subur di Dusun Ringinsari, Bokoharjo, Prambanan, Sleman, Yogyakarta. Pengambilan sampel pada penelitian ini yaitu menggunakan teknik sampling accidental sampling, 35 wanita usia subur di Dusun Ringinsari, Bokoharjo, Prambanan, Sleman, Yogyakarta. Pengambilan data menggunakan kuesioner yang diberikan kepada wanita usia subur tersebut dan analisa data menggunakan uji paired t-test.

\author{
a. Karakteristik Responden
}

Tabel 1. Umur Responden

\begin{tabular}{lcc}
\hline Umur & $\mathrm{N}$ & $(\%)$ \\
\hline 20-35 tahun & 19 & 54,29 \\
$>35$ tahun & 16 & 45,71 \\
\hline Total & 35 & 100 \\
\hline
\end{tabular}

Sumber : Data Primer (2019)

Tabel 1 menunjukkan mayoritas responden umur 20-35 tahun sebanyak 19 orang $(54,29 \%)$ dan usia $>35$ tahun sebanyak 16 orang $(45,71 \%)$.

\section{Tabel 2. Pendidikan Responden}

\begin{tabular}{ccc}
\hline Pendidikan & $\mathrm{N}$ & $(\%)$ \\
\hline Dasar & 14 & 31,43 \\
Menengah & 11 & 40 \\
Tinggi & 10 & 28,57 \\
\hline Total & 35 & 100 \\
\hline
\end{tabular}

Tabel 2 menunjukkan mayoritas responden mempunyai pendidikan menengah sebanyak 14 orang (40\%), berpendidikan dasar 11 orang $(31,43 \%)$ dan berpendidikan tinggi 10 respronden $(28,57 \%)$.

\section{Tabel 3. Pekerjaan Responden}


Vio Nita, Tutik Astuti "Perbedaan Pengetahuan Pre dan Post Penyuluhan Kesehatan Tentang Kanker Serviks pada Wanita di Dusun RinginSari Bokoharjo Prambanan Sleman Daerah Istimewa Yogyakarta" (hal 169-175)

\begin{tabular}{lcc}
\hline Pekerjaan & N & $(\%)$ \\
\hline IRT & 16 & 45,71 \\
Karyawan Swasta & 9 & 25,71 \\
Wiraswasta & 10 & 28,58 \\
\hline Total & 35 & 100 \\
\hline
\end{tabular}

Tabel 3 menunjukkan mayoritas responden mempunyai pekerjaan sebagai ibu rumah tangga sebanyak 16 orang $(45,71 \%)$, Karyawan swasta sebanyak 9 orang $(25,71 \%)$ dan wiraswasta 10 respronden $(28,58 \%)$.

Tabel 4. Tingkat Pengetahuan Sebelum Dilakukan Penyuluhan Kesehatan Tentang Kanker Serviks

\begin{tabular}{lll}
\hline Pengetahuan & $\mathrm{N}$ & $(\%)$ \\
\hline Baik & 4 & 11,43 \\
Cukup & 15 & 42,86 \\
Kurang & 16 & 45,71 \\
\hline Total & 35 & 100 \\
\hline
\end{tabular}

Diketahui sebagian besar pengetahuan sebelum dilakukan penyuluhan terkait dengan kanker serviks yaitu sebagian besar $45,71 \%$ dalam kategori kurang.

\section{Tabel 5. Tingkat Pengetahuan} Setelah Dilakukan Penyuluhan Kesehatan Tentang Kanker Serviks

\begin{tabular}{lll}
\hline Pengetahuan & $\mathrm{N}$ & $(\%)$ \\
\hline Baik & 25 & 71,43 \\
Cukup & 6 & 17,14 \\
Kurang & 4 & 11,43 \\
\hline Total & 35 & 100 \\
\hline
\end{tabular}

Berdasarkan tabel di atas diketahui bahwa sebagian besar 71,43\%

$$
\begin{aligned}
& \text { pengetahuan ibu setelah diberi } \\
& \text { penyuluhan tentang kanker serviks } \\
& \text { yaitu dalam kategori baik. }
\end{aligned}
$$

Tabel 6. Perbedaan Tingkat Pengetahuan Pre dan Post Test dilakukan Penyuluhan Kesehatan Tentang Kanker Serviks

\begin{tabular}{lcc}
\hline Pengetahuan & $\mathrm{N}$ & $p$-value \\
\hline Positif Ranks & 35 & \\
Negatif Ranks & 0 & 0,000 \\
Tics & 0 & \\
\hline Total & 35 & \\
\hline
\end{tabular}

Hasil dari analisis yang telah dilakukan dari 35 responden diketahui bahwa 35 orang responden mengalami peningkatan pengetahuan, tidak ada responden yang mengalami penurunan pengetahuan dan tidak ada nilai yang sama antara pre test dan post test. Diketahui nilai p-value $0,000<0,05$ yang berarti ada perbedaan antara pengetahuan tentang kanker serviks dan deteksi dini kanker serviks sebelum diberi penyuluhan dan setelah diberi penyuluhan.

Penyuluhan kesehatan tentang kanker serviks dan deteksi dini kanker serviks sangatlah penting dikarenakan bahwa dengan semakin banyak seseorang Page 173| 
Jurnal Kesehatan Karya Husada, No 7 Vol 2 Tahun 2019

PISSN 2337649X/EISSN 2655-8874

Vio Nita, Tutik Astuti "Perbedaan Pengetahuan Pre dan Post Penyuluhan Kesehatan Tentang Kanker Serviks pada Wanita di Dusun RinginSari Bokoharjo Prambanan Sleman Daerah Istimewa Yogyakarta" (hal 169-175)

mengetahui informasi atau yang tidak melakukan pemeriksaan pengetahuan tentang kanker serviks, maka semakin banyak pula para wanita usia subur khususnya dapat melakukan pemeriksaan secara dini untuk mencegah adanya keterlambatan dalam penanganan. Diketahui hasil analisis pre dan post test didapatkan nilai signifikansi 0,000 yang berarti bahwa ada perbedaan antara pengetahuan sebelum diberi penyuluhan dan setelah penyuluhan. Pendidikan kesehatan merupakan proses yang mencakup dimensi dan kegiatan-kegiatan intelektual, psikologi, dan sosial yang diperlukan untuk meningkatkan kemampuan individu dalam mengambil keputusan secara sadar dan yang mempengaruhi kesejahteraan diri, keluarga, dan masyarakat (Dermawan dan Setiawati, 2008). Pengetahuan sendiri adalah hasil "tahu"dan ini terjadi setelah orang mengadakan penginderaaan terhadap suatu obyek tertentu (Notoatmodjo dalam Dewi dan Wawan, 2010).

Banyak pengetahuan tentang deteksi dini kanker serviks, ibu menjadi banyak tahu tentang pentingnya pemeriksaan kanker serviks. Wanita kanker serviks dipengaruhi oleh beberapa faktor penyebab antara lain : faktor pengetahuan, faktor pendidikan, faktor usia dan faktor ekonomi.

Namun diketahui hal ini tidak cukup untuk mengubah suatu perilaku dikarenakan banyak faktor yang lainnya. Menurut Lawrence Green dalam Notoatmodjo (2010) terdapat faktor pendorong (predisposing faktors) merupakan faktor yang mempermudah atau mempredisposisi terjadinya perilaku seseorang, antara lain pengetahuan, sikap, keyakinan, kepercayaan, nilai-nilai, tradisi, dan sebagainya. Faktor pemungkin (enabling factors) merupakan faktor yang memungkinkan atau memfasilitasi perilaku atau tindakan. Faktor pemungkin maksudnya adalah sarana dan prasarana atau fasilitas untuk terjadinya perilaku kesehatan, misalnya: Puskesmas, Posyandu, Rumah Sakit, tempat pembuangan air, tempat pembuangan sampah, tempat olah raga, makanan bergizi, uang dan sebagainya. Faktor penguat (reinforcing factors) merupakan faktor 
Jurnal Kesehatan Karya Husada, No 7 Vol 2 Tahun 2019

PISSN 2337649X/EISSN 2655-8874

Vio Nita, Tutik Astuti "Perbedaan Pengetahuan Pre dan Post Penyuluhan Kesehatan Tentang Kanker Serviks pada Wanita di Dusun RinginSari Bokoharjo Prambanan Sleman Daerah lstimewa Yogyakarta" (hal 169-175)

yang mendorong atau memperkuat terjadinya perilaku.

\section{SIMPULAN DAN SARAN}

Pengetahuan yang baik seharusnya sejalan dengan perilaku yang baik yaitu melakukan pemeriksaan kanker serviks secara rutin. Pengetahuan dapat mempengaruhi seseorang secara ilmiah dan mendasari dalam mengambil keputusan rasional dan efektif dalam menerima perilaku baru yang akan menghasilkan persepsi yang positif dan negatif.

\section{DAFTAR PUSTAKA}

Arifin Zainal, 2014. Penelitian Pendidikan. Bandung : Remaja Rosdakarya

Darmawan, A.C dan Setiawati. (2008)

Proses pembelajaran dalam pendidikan kesehatan. Jakarta: Trans info media

Delia, 2010. Pembunuh Ganas Itu Bernama Kanker Serviks. Jakarta : Sinar Kejora

Depkes, 2013. Riset Kesehatan

Dasar (Riskesdas). Jakarta :

Kemenkes
Dewi, M dan Wawan, A. (2010). Teori dan pengukuran pengetahuan, sikap, dan perilaku manusia. Yogyakarta: Nuha Medika IARC (InternationalAgency For Research On Cancer). 2012. Estimated Cancer Incidence, Mortality and Prevalence Wordwide in 2012. http://globocan.iarc.fr/Default.asp $\underline{\mathrm{x}}$, diakses pada tanggal 24 Februari 2018

Kementerian Kesehatan Indonesia. 2017.Profil Kesehatan

Indonesia Tahun 2016. Jakarta :

Kemenkes Indonesia

Novel S. Sinta, dkk. 2010.Kanker Serviks dan Infeksi Human Pappilomavirus (HPV). Jakarta : Javamedia Network Sugiyono, 2012. Statistik Untuk

Penelitian. Bandung : Alfabeta 